\title{
Efeito da adição de areia de fundição e cal em algumas propriedades de solos argilosos
}

\author{
Luis Miguel Gutiérrez Klinsky ${ }^{1}$, Ana Paula Furlan² e Glauco Tulio Pessa Fabbri ${ }^{3}$
}

\begin{abstract}
Resumo: Os elevados custos de descarte da areia de fundição e as suas boas propriedades para utilização em construção civil têm estimulado pesquisas de alternativas para o seu reuso e, nesse sentido, a construção de pavimentos oferece oportunidades para que a areia de fundição seja reaproveitada. Assim, este trabalho conduziu um programa laboratorial de ensaios para avaliar algumas propriedades mecânicas de interesse à engenharia de pavimentos de misturas de areia de fundição com solos argilosos e cal, para sua possível utilização como material de construção de camadas de pavimentos. Os resultados obtidos mostram que solos argilosos lateríticos misturados com 60 e $70 \%$ de areia de fundição poderiam ser utilizados em bases e sub-bases de pavimentos de baixo volume de tráfego e que solos argilosos não lateríticos misturados com 40, 60 e 70\% do resíduo e estabilizados com cal, também poderiam ser utilizados em sub-bases de pavimentos de baixo volume de tráfego.
\end{abstract}

Palavras-chave: areia de fundição residual, cal, solos argilosos.

Abstract: The good engineering properties of foundry sand and the high costs of landfilling have stimulated the researchers to find new alternatives for foundry sand reuse. Pavement construction offers opportunities for the beneficial reuse of this residue. In that way, this paper presents the results of a laboratory testing program to asses some properties of sand-clayey soils stabilized with lime, according to some pavement engineering properties and focusing on their applicability as low volume traffic road bases and sub-bases materials. The results show that Clayey Lateritic Soils mixed with 60 and $70 \%$ of Foundry Sand could be used as pavement bases and subbases and, Clayey Non Lateritic Soils mixed with 40, 60 and 70\% of Foundry Sand and stabilized with lime could be used as pavement sub-bases in low volume traffic roads.

Keywords: waste foundry sand, lime, clayey soils.

\section{INTRODUÇÃO}

A indústria de fundição utiliza areia para confeccionar os moldes nos quais são fundidas as peças metálicas. As razões do uso de areias são várias, já estão prontas para serem usadas, são altamente refratárias e apresentam baixo custo. A degradação granulométrica da areia durante o processo de fundição e o uso de aditivos limitam o seu reuso no próprio processo, motivo pelo qual o descarte se faz necessário para as empresas siderúrgicas. Esse descarte geralmente é realizado em aterros sanitários a altos custos, além da perda de um material de boas propriedades do ponto de vista de utilização em engenharia.

No Brasil, a produção de fundidos superou as três milhões de toneladas no ano 2010 (ABIFA, 2011) e segundo McIntyre et al. (1992), para cada tonelada de metal fundido se tem, aproximadamente, uma tonelada de areia de descarte. Pode-se afirmar, portanto, que a menos que sejam aplicadas novas alternativas de uso para este resíduo, os custos de descarte continuarão aumentando.

Alguns estudos têm sido realizados com a intenção de reutilizar a areia de fundição na engenharia civil. Nesse sentido, a construção de pavimentos é uma das alternativas que permite reaproveitar maiores volumes deste resíduo.

\footnotetext{
${ }^{1}$ Luis Miguel Gutiérrez Klinsky, Departamento de Engenharia de Transportes, Escola de Engenharia de São Carlos, Universidade de São Paulo, São Carlos, SP, Brasil. (e-mail: chiligk@gmail.com).

${ }^{2}$ Ana Paula Furlan, Departamento de Engenharia de Transportes, Escola de Engenharia de São Carlos, Universidade de São Paulo, São Carlos, SP Brasil. (e-mail: afurlan@sc.usp.br).

${ }^{3}$ Glauco Tulio Pessa Fabbri, Departamento de Engenharia de Transportes, Escola de Engenharia de São Carlos, Universidade de São Paulo, São Carlos, SP, Brasil. (e-mail: glauco@sc.usp.br).
}

Manuscrito recebido em 5/2/2012 e aprovado para publicação em 24/4/2012. Este artigo é parte de TRANSPORTES v. 20, n. 1, 2012. ISSN: 2237-1346 (online).
Assim, na busca do uso benéfico deste resíduo, este trabalho tem como objetivo avaliar misturas de areia de fundição com solos argilosos, com a eventual adição de cal como agente estabilizante, à luz de algumas propriedades mecânicas da engenharia de pavimentos, visando o uso dos materiais resultantes na construção de estradas.

\section{REVISÃO BIBLIOGRÁFICA}

No Brasil muitas regiões apresentam solos que não exibem as características adequadas para seu emprego como bases de pavimentos. No entanto, esses solos, quando misturados com outros materiais ou com agentes estabilizadores, podem produzir materiais adequados para uso em camadas de pavimentos. Corrêa (1989) estudou a possibilidade de misturar Latossolo Roxo com areia a fim de produzir um material semelhante ao "Latossolo Roxo de Transição". Segundo esse autor, esse tipo de mistura, solo-areia, apresenta um comportamento estruturado do tipo macadame, com boa compatibilidade entre o volume de finos e o volume final de vazios da estrutura granular arenosa. Por outro lado, a adição de solos argilosos à areia reduz o atrito entre os grãos, provocado pela "lubrificação resultante da proximidade da umidade ótima do solo".

Corrêa (1989) concluiu que misturas solo-areia com mais de $50 \%$ de areia laterítica na sua constituição apresentavam comportamentos semelhantes aos dos Solos Arenosos Finos Lateríticos. Entretanto, no caso em que quantidade da fração do solo argiloso era superior à da de areia, eram obtidas misturas solo-areia com comportamentos semelhantes à matriz do solo que os constituía e, portanto, esses materiais poderiam ser estabilizados com algum agente estabilizante, a cal, por exemplo.

A estabilização de solos finos com a cal pode ser uma alternativa de custo relativamente baixo, se comparada às so- 
luções tradicionais, tais como o emprego de cimento Portland, cimento asfáltico ou o transporte de grandes volumes de materiais mais nobres. Sua utilização iniciou-se nos Estados Unidos na década de 1920 e, no Brasil, os primeiros relatos datam do final da década de 1960.

De acordo com a National Lime Association (2006), a estabilização de solos finos com cal leva a um aumento da resistência em longo prazo e reduz a plasticidade e a expansão do solo. Os efeitos da estabilização com cal são notórios após 28 dias de cura ou mais, mas este período de cura poderia ser acelerado se a temperatura for aumentada.

Alguns trabalhos têm procurado utilizar cal na estabilização de resíduos com o propósito da sua utilização em camadas de pavimentos. Oliveira (2005), por exemplo, estudou o comportamento mecânico de misturas de fosfogesso e cal para utilização na construção rodoviária. Nesse trabalho a autora relata que o efeito positivo da cal torna-se realmente significativo para o teor de $3 \%$.

Leandro (2005) desenvolveu um estudo laboratorial acerca da possibilidade de aproveitamento da cinza pesada, produzida em termelétricas, em bases e sub-bases de pavimentos. Os resultados obtidos por este autor mostraram que a adição de cinza pesada aos solos não melhorou as propriedades mecânicas das misturas compactadas; já, a adição de $3 \%$ de cal às misturas de solo-cinza proporcionou uma melhora significativa no comportamento mecânico das misturas.

\section{MATERIAIS E MÉTODOS}

A areia de fundição (AF) utilizada neste trabalho foi fornecida pela Siderúrgica Dedini, localizada na cidade de Piracicaba, no interior do Estado de São Paulo. Essa areia é classificada como Classe II A - Resíduo Não Inerte (NBR 10004:2004). A técnica empregada por esta Siderúrgica na confecção dos moldes para a fundição das peças é a de moldagem em Areia de Macho com adição de resina furânica. Esta empresa, em 2008, produziu aproximadamente 27.000 toneladas de peças fundidas; para isso, utilizou cerca de 29.000 toneladas de areia reciclada e 26.000 toneladas de areia virgem (Dedini, 2008).
Foram utilizados dois solos argilosos neste estudo, um deles classificado segundo a metodologia MCT (Miniatura, Compactado, Tropical) como Laterítico Argiloso (LG') e o outro como Não Laterítico Argiloso (NG'); os dois solos foram coletados próximos à cidade de Piracicaba/SP. A cal utilizada na estabilização dos solos foi da marca Supercal, do tipo CH-I. A Figura 1 apresenta as distribuições granulométricas dos solos e do resíduo areia de fundição da Siderúrgica Dedini.

Para desenvolver este estudo foi utilizada a técnica de composição de misturas de solos em laboratório. Assim, foram confeccionados dois conjuntos de solo-areia e dois conjuntos de solo-areia-cal, totalizando quatro grupos de misturas, a saber:

a. Solo Argiloso Laterítico + \% de Areia de Fundição (LG'+AF\%);

b. Solo Argiloso Não Laterítico + \% de Areia de Fundição (NG'+AF\%);

c. Solo Argiloso Laterítico + \% de Areia de Fundição $+3 \%$ de $\mathrm{Cal}\left(\mathrm{LG}{ }^{\prime}+\mathrm{AF} \%+\mathrm{Cal}\right) ; \mathrm{e}$

d. Solo Argiloso Não Laterítico + \% de Areia de Fundição + 3\% de Cal (NG'+AF\%+Cal).

Para a avaliação das características e propriedades das misturas solo-areia e solo-areia-cal foram executados ensaios de massa específica dos sólidos, granulometria, limites de consistência, mini-MCV e perda de massa por imersão (classificação MCT), mini-CBR e associados (com e sem imersão, expansão, contração) e triaxial cíclico.

\section{APRESENTAÇÃO E ANÁLISE DOS RESULTADOS}

Inicialmente foram executados os ensaios de massa específica dos sólidos, granulometria e limites de consistência das misturas solo-areia e solo-areia-cal. Os resultados destes ensaios encontram-se resumidos na Tabela 1. Embora as classificações de solos tenham sido desenvolvidas para materiais naturais, elas foram utilizadas neste trabalho para indicar ou fornecer uma previsão do comportamento para utilização em pavimentos. Assim, ainda na Tabela 1, são apre-

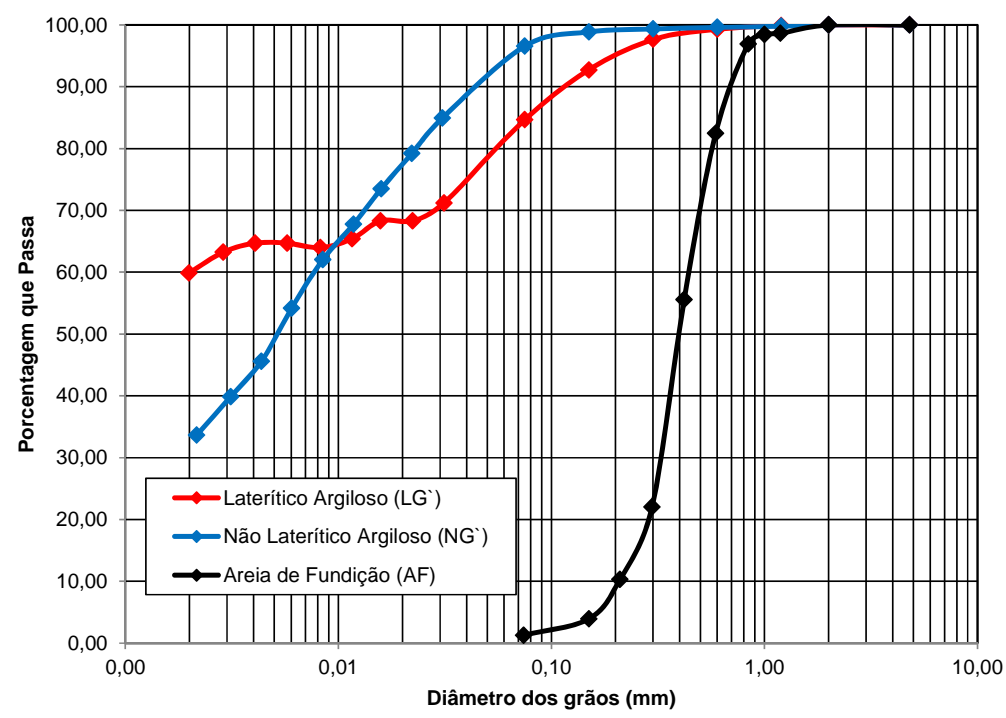

Figura 1. Distribuições granulométricas dos solos argilosos e da areia de fundição 
sentadas as classes das misturas segundo as classificações USCS (Unified Soil Classification System) e TRB (Transportation Research Board).

Vários estudos de estabilização de solos com cal relatam as diminuições do Limite de Liquidez (LL) e do Índice de Plasticidade (IP) em função da adição e do acréscimo do teor de cal (Thompson, 1970; Lima, 1981; Corrêa, 1989; Yusuf et al., 2001 e Guney et al., 2006). Essa redução dos limites de consistência foi também constatada nos resultados obtidos neste estudo, porém, não foi tão significativa quanto à relatada pelos autores citados; a redução do LL e do IP foi mais notória com o aumento da porcentagem de areia de fundição adicionada ao solo Laterítico Argiloso (LG') e ao solo Não Laterítico Argiloso (NG'), como pode ser notado na Tabela 1 e na Figura 2. Na Figura 2 é possível constatar ainda que a redução do IP com a adição de $3 \%$ de cal foi mais expressiva para o solo NG'.

A Figura 3 mostra as classes MCT para as misturas dos dois solos com os vários teores de areia de fundição ( $0 \%$, $20 \%, 40 \%, 60 \%$ e $70 \%$ ) e também com adição de 3\% de cal. Nela pode-se notar que as misturas solo-areia com o solo NG' foi mais sensível à adição de cal, resultando em misturas classificadas como solos de comportamento laterítico, segundo a MCT. De modo geral, a adição de areia de fundição ao solo LG’ reduziu sua argilosidade, produzindo alguns solos classificados como LA'.

O ensaio de mini-CBR foi executado na energia intermediária de compactação. Deste ensaio foram obtidos os va-

Tabela 1. Resultados dos ensaios de massa específica dos sólidos, granulometria e limites de consistência

\begin{tabular}{|c|c|c|c|c|c|c|c|c|c|c|}
\hline MATERIAL & $\begin{array}{l}\text { Massa } \\
\text { Esp. dos } \\
\text { Sólidos } \\
\left(\mathrm{gr} / \mathrm{cm}^{3}\right)\end{array}$ & $\begin{array}{l}L L \\
(\%)\end{array}$ & $\begin{array}{l}L P \\
(\%)\end{array}$ & $\begin{array}{l}I P \\
(\%)\end{array}$ & $\begin{array}{l}\text { Pass. } \\
\text { No.4 } \\
(\%)\end{array}$ & $\begin{array}{l}\text { Pass. } \\
\text { No.10 } \\
(\%)\end{array}$ & $\begin{array}{l}\text { Pass. } \\
\text { No. } 40 \\
(\%)\end{array}$ & $\begin{array}{l}\text { Pass. } \\
\text { No. } 200 \\
\text { (\%) }\end{array}$ & $\begin{array}{l}\text { Class. } \\
\text { TRB }\end{array}$ & $\begin{array}{l}\text { Class. } \\
\text { USCS }\end{array}$ \\
\hline $\mathrm{LG}^{\prime}$ & 2,825 & 46 & 33 & 13 & 100 & 100 & 98 & 85 & A-7-5 & ML \\
\hline$L G^{\prime}+20 \%$ & 2,775 & 39 & 26 & 13 & 100 & 100 & 90 & 68 & A-6 & ML \\
\hline$L^{\prime}+40 \%$ & 2,751 & 34 & 23 & 11 & 100 & 100 & 82 & 55 & A-6 & ML-CL \\
\hline $\mathrm{LG}^{\prime}+60 \%$ & 2,737 & 29 & 19 & 10 & 100 & 100 & 75 & 42 & A-4 & SC \\
\hline $\mathrm{LG}^{\prime}+70 \%$ & 2,701 & 23 & 16 & 7 & 100 & 100 & 70 & 27 & A-2-4 & SM-SC \\
\hline $\mathrm{LG}^{\prime}+\mathrm{Cal}$ & 2,574 & 42 & 31 & 11 & 100 & 100 & 86 & 52 & A-7-5 & ML \\
\hline $\mathrm{LG}^{\prime}+20 \%+\mathrm{Cal}$ & 2,647 & 38 & 26 & 12 & 100 & 100 & 87 & 52 & A-6 & CL \\
\hline $\mathrm{LG}^{\prime}+40 \%+\mathrm{Cal}$ & 2,717 & 33 & 24 & 9 & 100 & 100 & 74 & 27 & A-2-4 & SM-SC \\
\hline $\mathrm{LG}^{\prime}+60 \%+\mathrm{Cal}$ & 2,732 & 25 & 19 & 6 & 100 & 100 & 70 & 26 & A-2-4 & SM-SC \\
\hline $\mathrm{LG}^{\prime}+70 \%+\mathrm{Cal}$ & 2,764 & 21 & 15 & 6 & 100 & 100 & 65 & 13 & A-2-4 & SM-SC \\
\hline$N G^{\prime}$ & 2,745 & 58 & 34 & 24 & 100 & 100 & 99 & 97 & A-7-5 & $\mathrm{MH}$ \\
\hline$N^{\prime}+20 \%$ & 2,725 & 52 & 32 & 20 & 100 & 100 & 93 & 80 & A-7-5 & $\mathrm{MH}$ \\
\hline $\mathrm{NG}^{\prime}+40 \%$ & 2,713 & 44 & 27 & 17 & 100 & 100 & 82 & 60 & A-7-5 & CL \\
\hline $\mathrm{NG}^{\prime}+60 \%$ & 2,706 & 35 & 21 & 14 & 100 & 100 & 74 & 41 & A-6 & CL \\
\hline $\mathrm{NG}^{\prime}+70 \%$ & 2,698 & 33 & 21 & 12 & 100 & 100 & 73 & 36 & A-6 & CL \\
\hline NG'+Cal & 2,617 & 57 & 38 & 19 & 100 & 100 & 92 & 85 & A-7-5 & $\mathrm{MH}$ \\
\hline $\mathrm{NG}^{\prime}+20 \%+\mathrm{Cal}$ & 2,612 & 46 & 33 & 13 & 100 & 100 & 90 & 71 & A-7-5 & $\mathrm{MH}$ \\
\hline $\mathrm{NG}^{\prime}+40 \%+\mathrm{Cal}$ & 2,663 & 43 & 32 & 11 & 100 & 100 & 80 & 52 & A-7-5 & CL \\
\hline $\mathrm{NG}^{\prime}+60 \%+\mathrm{Cal}$ & 2,691 & 34 & 25 & 9 & 100 & 100 & 73 & 38 & A-4 & $\mathrm{SM}$ \\
\hline $\mathrm{NG}^{\prime}+70 \%+\mathrm{Cal}$ & 2,741 & 29 & 20 & 9 & 100 & 100 & 68 & 25 & A-2-4 & SM-SC \\
\hline
\end{tabular}

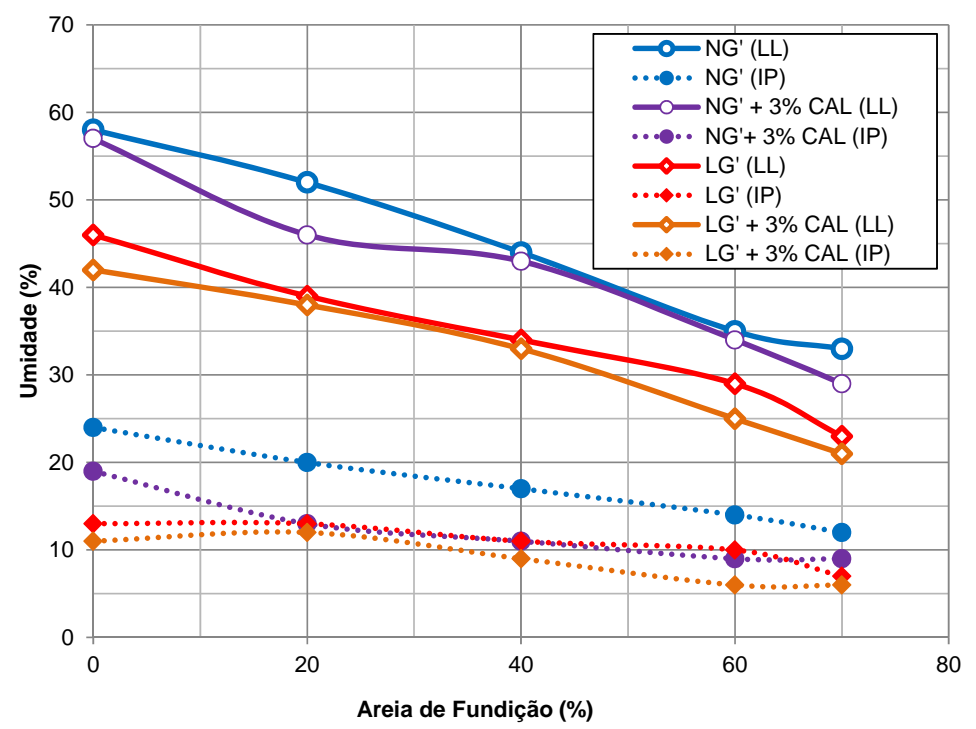

Figura 2. Limites de consistência das misturas solo-areia e solo-areia-cal 

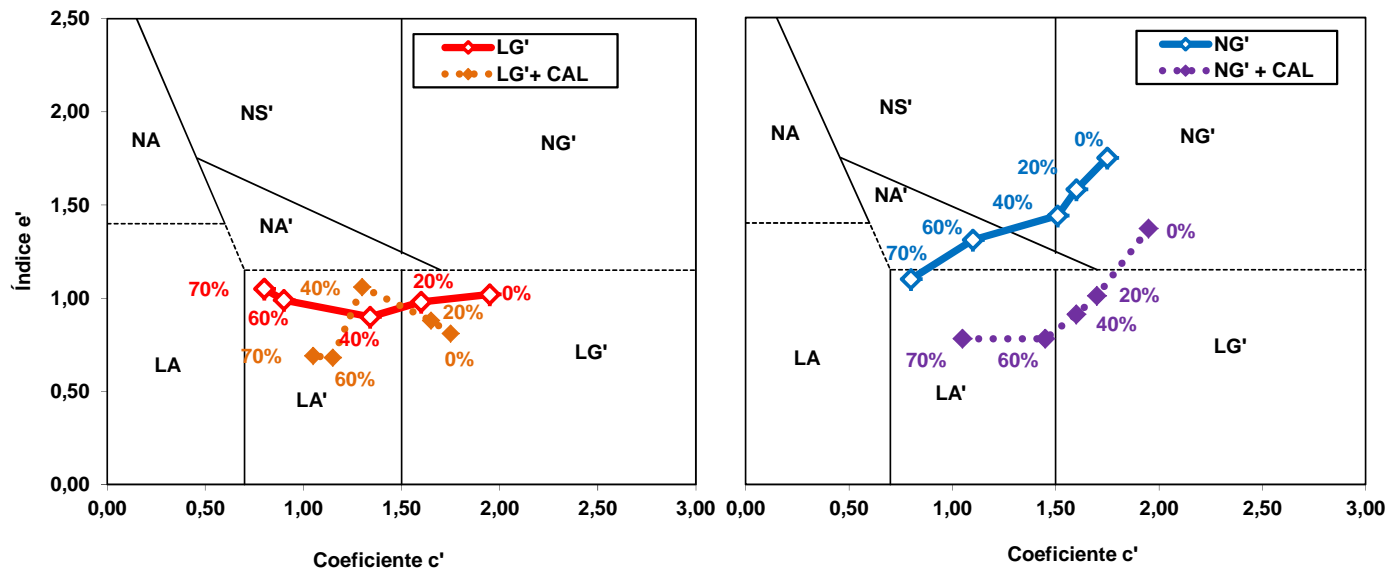

Figura 3. Classificação MCT das misturas solo-areia e solo-areia-cal

lores de massa específica seca máxima $\left(\mathrm{MES}_{\max }\right)$ e umidade ótima $\left(\mathrm{W}_{\mathrm{ot}}\right)$ das misturas solo-areia e solo-areia cal. As Figuras $4 \mathrm{a}$ e $4 \mathrm{~b}$ ilustram a variação da $\mathrm{W}_{\mathrm{ot}}$ dos solos $L G^{\prime}$ e NG', respectivamente. Nas figuras nota-se que, independente do tipo de solo empregado nas misturas, a adição e o aumento da porcentagem de areia de fundição diminui a umidade ótima, além disso, verifica-se que a adição de 3\% de cal às misturas solo-areia causou aumento das umidades ótimas, como observado por Thompson (1970), Li- ma (1981), Corrêa (1989), Yusuf et al. (2001) e Guney et al. (2006).

As Figuras $5 a$ e $5 b$ apresentam os resultados de massas específicas secas máximas para os solos LG' e NG', respectivamente. Nessas Figuras observa-se que o aumento do teor de areia de fundição eleva os valores de $\mathrm{MES}_{\max }$ para os dois solos, tanto para os grupos solo-areia quanto para os solo-areia-cal. Constata-se também que a adição de cal reduz a massa específica seca máxima, como relatado na

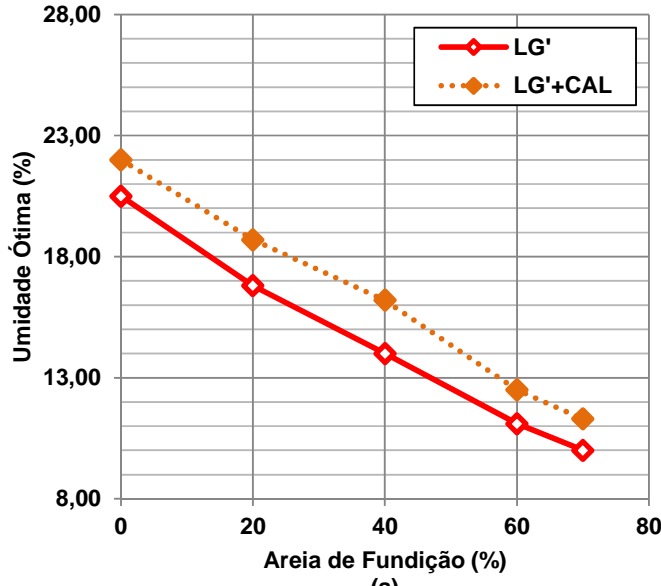

(a)

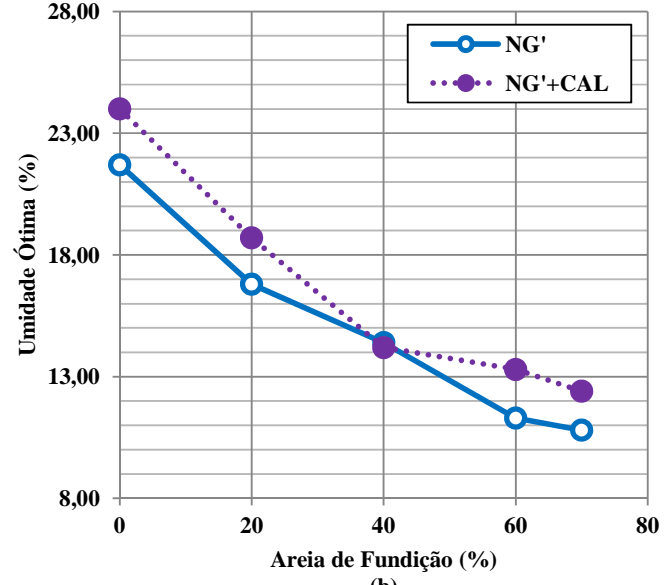

(b)

Figura 4. Variação da umidade ótima $\left(\mathrm{W}_{\mathrm{ot}}\right)$ das misturas solo-areia e solo-areia-cal

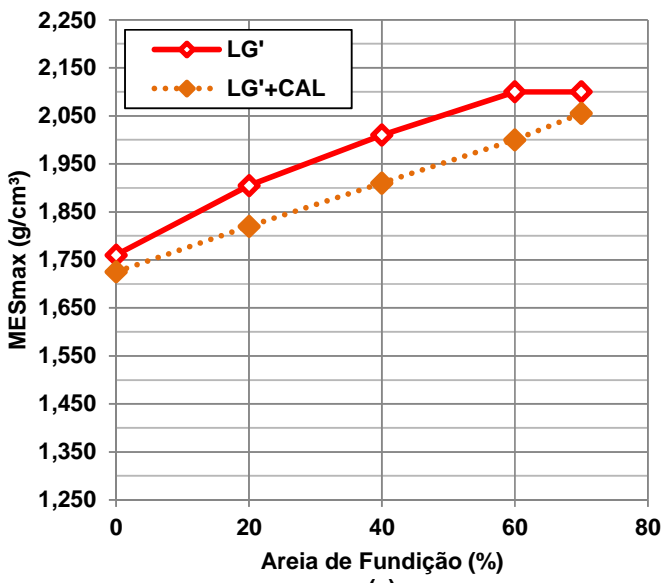

(a)

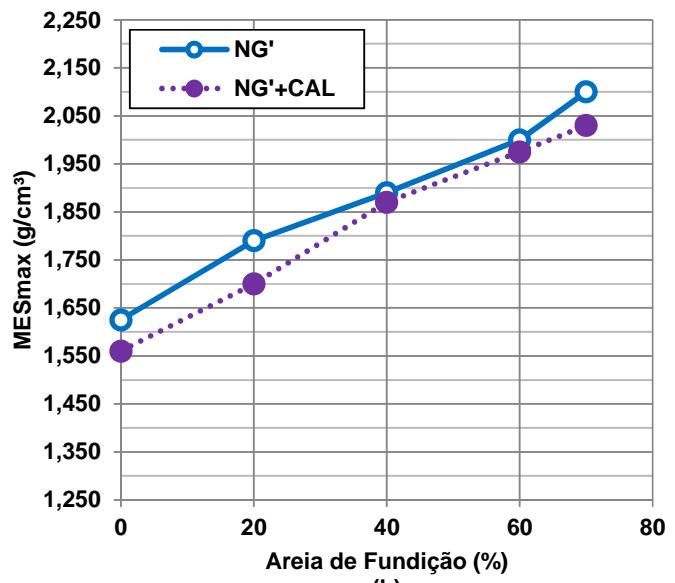

(b)

Figura 5. Variação da $\mathrm{MES}_{\max }$ nas misturas solo-areia e solo-areia-cal 
bibliografia.

Os valores de mini-CBR, expansão e contração, para o grupo das misturas solo-areia, foram determinados sob duas condições: I) mini-CBR imediato e II) mini-CBR após imersão por 24 horas. Já para as misturas solo-areia-cal foi acrescentada uma terceira condição: III) mini-CBR após 24 horas de cura em câmara úmida e imersão por 24 horas, adotada para avaliar o efeito da adição de cal nas misturas. Os resultados são apresentados nas Figuras 6a e 6b, onde nota-se que os valores de mini-CBR imediato das misturas solo-areia não apresentaram uma tendência clara de comportamento em função do incremento da areia de fundição; contudo, na condição de 24 horas de imersão, os valores de mini-CBR mostraram uma tendência de aumento com o aumento da porcentagem de resíduo adicionada.

Pode-se notar ainda nas Figuras 6a e 6b, que as misturas do grupo solo-areia-cal apresentaram valores de mini-CBR imediato (Condição I) e mini-CBR após imersão por 24 horas (Condição II) bastante superiores aos das misturas soloareia, para todos os teores de areia de fundição adicionada. De maneira geral, os valores de mini-CBR após 24 horas de cura em câmara úmida e imersão por 24 horas (Condição

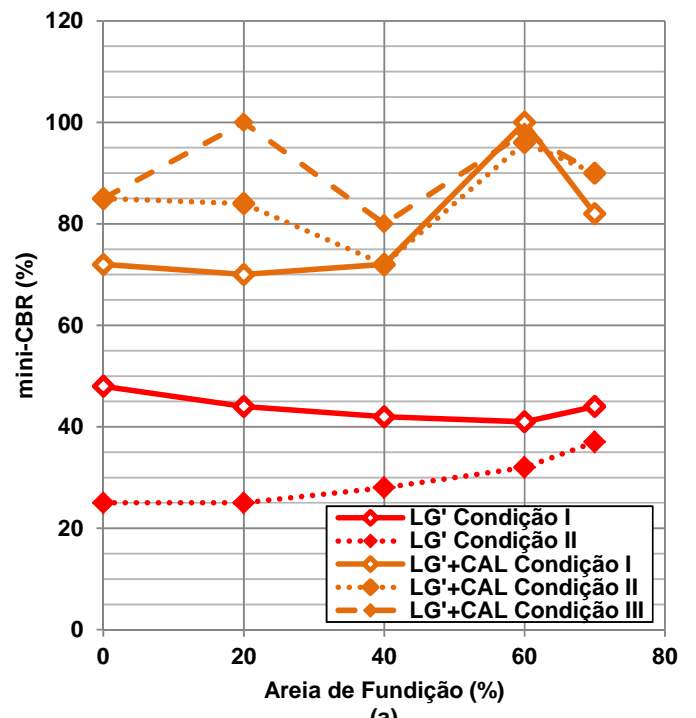

(a)
III) foram maiores que os valores obtidos para a Condição II e Condição I, o que demonstra a importância da cura para solos estabilizados com cal.

Os valores de expansão (nas Condições II e III) e de contração, dos grupos solo-areia e solo-areia-cal são apresentados nas Figuras 7a e 7b, onde constata-se que o incremento de areia de fundição reduziu tanto os valores de expansão como os de contração. No que se refere a comportamentos particulares, vale destacar que:

- a expansão do solo NG' é consideravelmente maior que a do solo LG';

- a contração das misturas solo-areia é semelhante para os dois solos estudados;

- a adição de cal às misturas solo-areia tende a reduzir ou eliminar a expansão apresentada nas Condições II e III; e

- a adição de 3\% de cal diminuiu a contração das misturas solo-areia-cal, contudo foi mais notória para as misturas com solo LG'.

O ensaio de resistência à compressão simples (RCS) foi executado somente em corpos-de-prova do grupo solo-

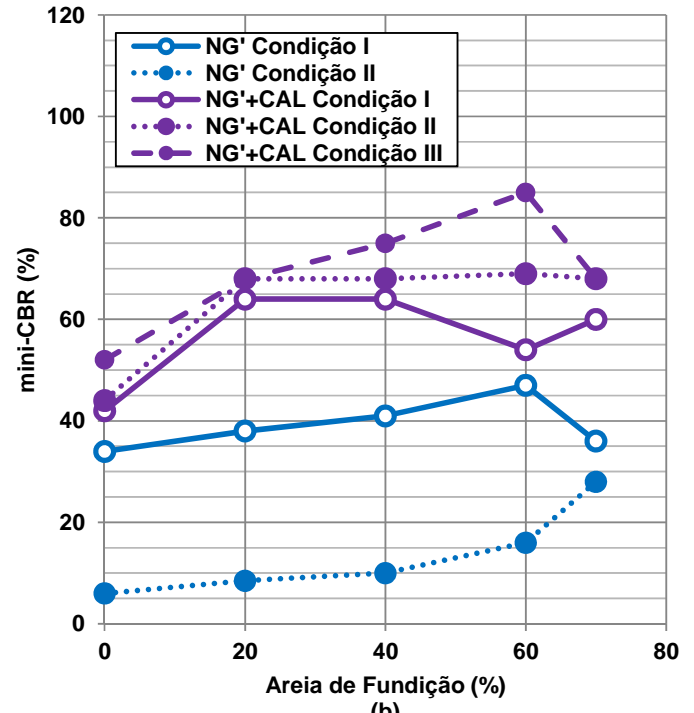

(b)

Figura 6. Valores de mini-CBR obtidos nas misturas solo-areia e solo-areia-cal

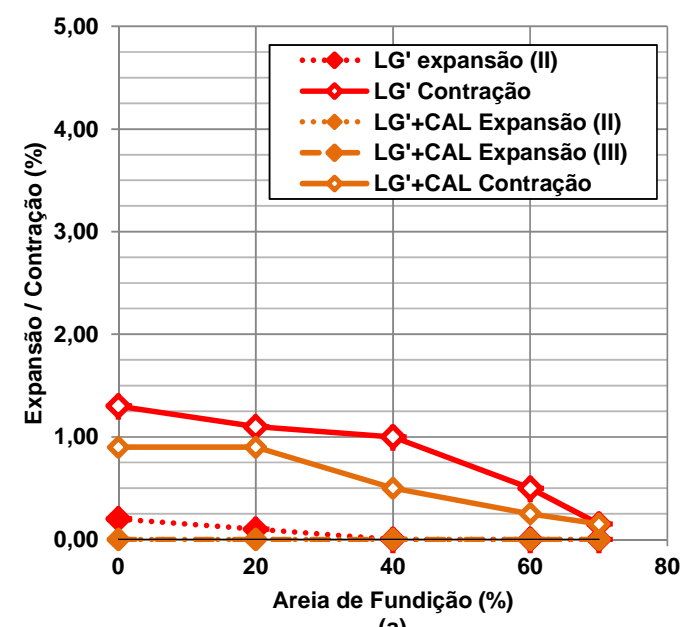

(a)

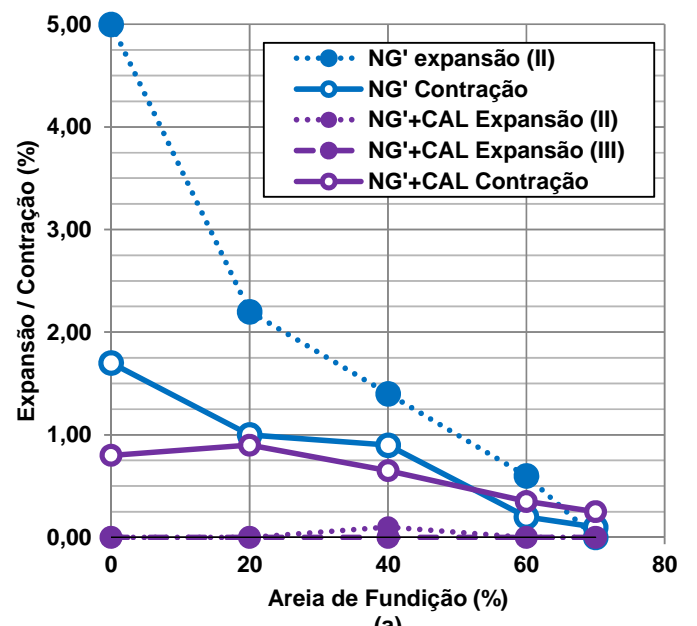

(a)

Figura 7. Valores de expansão e contração para as misturas solo-areia e solo-areia-cal 
areia-cal confeccionados a partir dos solos LG' e NG'. Para a execução deste ensaio foram utilizados os valores de $\mathrm{MES}_{\max }$ e $\mathrm{W}_{\text {ot }}$ obtidos no ensaio de mini-CBR na energia intermediária. Às misturas solo-areia foi adicionado 3\% de cal, a seco, e, posteriormente, foi adicionada a água necessária para alcançar a $\mathrm{W}_{\text {ot, }}$, sendo que, em seguida, procedeuse à compactação para produzir corpos-de-prova de 10,0 cm de altura por 5,0 cm de diâmetro.

Para avaliar o incremento da RCS das misturas soloareia-cal com o decorrer do tempo, foram estudados quatro tempos de cura (0, 3, 7 e 28 dias). Para cada tempo de cura foram compactados seis corpos-de-prova, de maneira que três fossem ensaiados na condição seca (A) e três na condição após 4 horas de imersão (B). A Tabela 2 mostra a média das RCS obtidas nas condições (A) e (B), assim como a relação (B)/(A), que fornece uma estimativa do dano causado pela água nas misturas devido à imersão. Nota-se, nessa Tabela, o aumento constante do valor da RCS com o tempo de cura. Entretanto, para a mistura LG'+70\%+Cal observa-se uma RCS ligeiramente maior aos 3 dias de cura do que aos 7 dias, isto pode ser explicado devido à reduzida quantidade da fração argilosa laterítica presente, cuja influência na RCS é proporcional à sua quantidade e ao tempo de cura.

Os valores apresentados na Tabela 2 são ilustrados nas Figuras 8a e 8b, com os valores de tempo de cura no eixo horizontal, em escala logarítmica, e os valores de RCS no eixo vertical, em escala aritmética. Nessas figuras observase que a RCS aumenta com o tempo de cura e alcança valores máximos no maior tempo de cura estudado, 28 dias, para todas as misturas solo-areia-cal. É possível observar ainda, que as perdas de resistência pela imersão dos corposde-prova em água durante 4 horas são maiores nas misturas solo-areia-cal que têm como matriz o solo NG', quando comparadas às das misturas solo-areia-cal com solo LG'.

As Figuras 9a e 9b mostram os resultados dos ensaios de RCS para os grupos solo-areia-cal a 0 e 28 dias de cura, respectivamente. Nessas figuras nota-se que valores máximos de RCS (A) e RCS (B) foram apresentados pelas misturas com a matriz LG' e com $0 \%$ e $20 \%$ de Areia de Fundição (AF), a partir desse teor de resíduo, as resistências decrescem, tanto para 0 como para 28 dias de cura. Por outro lado, as misturas com matriz NG' apresentam RCS (A) e RCS (B) crescentes até o teor de 40\% de Areia de Fundição, a partir desse teor as resistências diminuem, essa tendência é observada nos dois tempos de cura comparados, 0 e 28 dias.

Além disso, cabe notar que aos 28 dias de cura todas as misturas solo-areia-cal mostraram um incremento na RCS. Notou-se ainda que as misturas solo-areia-cal compostas a partir do solo NG' apresentaram as maiores perdas de RCS devida à imersão por 4 horas (Condição B).

Tabela 2. Resistência à compressão simples para as misturas solo-areia-cal

\begin{tabular}{|c|c|c|c|c|c|c|c|}
\hline \multicolumn{4}{|c|}{$L G^{\prime}+C A L$} & \multicolumn{4}{|c|}{$N G^{\prime}+C A L$} \\
\hline CURA & $\begin{array}{l}R C S(A) \\
(k P a)\end{array}$ & $\begin{array}{l}R C S(B) \\
(k P a)\end{array}$ & $\begin{array}{l}\text { Relação } \\
(B) /(A)\end{array}$ & CURA & $\begin{array}{l}R C S(A) \\
(k P a)\end{array}$ & $\begin{array}{l}R C S(B) \\
(k P a)\end{array}$ & $\begin{array}{l}\text { Relação } \\
(B) /(A)\end{array}$ \\
\hline 0 & 1177 & 415 & 0,35 & 0 & 732 & 153 & 0,21 \\
\hline 3 & 1373 & 997 & 0,73 & 3 & 902 & 482 & 0,53 \\
\hline 7 & 1420 & 1052 & 0,74 & 7 & 1050 & 565 & 0,54 \\
\hline 28 & 1634 & 1065 & 0,65 & 28 & 1536 & 876 & 0,57 \\
\hline \multicolumn{4}{|c|}{$L G^{\prime}+20 \%+C A L$} & \multicolumn{4}{|c|}{$N G^{\prime}+20 \%+C A L$} \\
\hline CURA & $\begin{array}{l}R C S(A) \\
(k P a)\end{array}$ & $\begin{array}{l}R C S(B) \\
(k P a)\end{array}$ & $\begin{array}{l}\text { Relação } \\
(B) /(A) \\
\end{array}$ & CURA & $\begin{array}{l}R C S(A) \\
(k P a)\end{array}$ & $\begin{array}{l}R C S(B) \\
(k P a)\end{array}$ & $\begin{array}{l}\text { Relação } \\
(B) /(A) \\
\end{array}$ \\
\hline 0 & 1176 & 626 & 0,53 & 0 & 1122 & 116 & 0,10 \\
\hline 3 & 1264 & 967 & 0,77 & 3 & 1339 & 655 & 0,49 \\
\hline 7 & 1277 & 1054 & 0,83 & 7 & 1357 & 762 & 0,56 \\
\hline 28 & 1491 & 1063 & 0,71 & 28 & 1899 & 1202 & 0,63 \\
\hline \multicolumn{4}{|c|}{$L G^{\prime}+40 \%+C A L$} & \multicolumn{4}{|c|}{$N G^{\prime}+40 \%+C A L$} \\
\hline CURA & $\begin{array}{l}\text { RCS (A) } \\
(\mathrm{kPa})\end{array}$ & $\begin{array}{l}R C S(B) \\
(k P a)\end{array}$ & $\begin{array}{l}\text { Relação } \\
(B) /(A)\end{array}$ & CURA & $\begin{array}{l}R C S(A) \\
(k P a)\end{array}$ & $\begin{array}{l}R C S(B) \\
(k P a)\end{array}$ & $\begin{array}{l}\text { Relação } \\
(B) /(A)\end{array}$ \\
\hline 0 & 662 & 344 & 0,52 & 0 & 1249 & 112 & 0,09 \\
\hline 3 & 679 & 449 & 0,66 & 3 & 1391 & 570 & 0,41 \\
\hline 7 & 707 & 504 & 0,71 & 7 & 1523 & 698 & 0,46 \\
\hline 28 & 924 & 770 & 0,83 & 28 & 1955 & 1357 & 0,69 \\
\hline \multicolumn{4}{|c|}{$L G^{\prime}+60 \%+C A L$} & \multicolumn{4}{|c|}{$N G^{\prime}+60 \%+C A L$} \\
\hline CURA & $\begin{array}{l}R C S(A) \\
(k P a)\end{array}$ & $\begin{array}{l}R C S(B) \\
(k P a)\end{array}$ & $\begin{array}{l}\text { Relação } \\
(B) /(A)\end{array}$ & CURA & $\begin{array}{l}R C S(A) \\
(k P a)\end{array}$ & $\begin{array}{l}R C S(B) \\
(k P a)\end{array}$ & $\begin{array}{l}\text { Relação } \\
(B) /(A)\end{array}$ \\
\hline 0 & 372 & 166 & 0,45 & 0 & 490 & 90 & 0,18 \\
\hline 3 & 455 & 300 & 0,66 & 3 & 644 & 311 & 0,48 \\
\hline 7 & 495 & 373 & 0,75 & 7 & 679 & 322 & 0,47 \\
\hline 28 & 639 & 467 & 0,73 & 28 & 1033 & 804 & 0,78 \\
\hline \multicolumn{4}{|c|}{$L G^{\prime}+70 \%+C A L$} & \multicolumn{4}{|c|}{$N G^{\prime}+70 \%+C A L$} \\
\hline CURA & $\begin{array}{l}R C S(A) \\
(k P a)\end{array}$ & $\begin{array}{l}R C S(B) \\
(k P a)\end{array}$ & $\begin{array}{l}\text { Relação } \\
(B) /(A)\end{array}$ & CURA & $\begin{array}{l}R C S(A) \\
(k P a)\end{array}$ & $\begin{array}{l}R C S(B) \\
(k P a)\end{array}$ & $\begin{array}{l}\text { Relação } \\
(B) /(A)\end{array}$ \\
\hline 0 & 220 & 116 & 0,52 & 0 & 339 & 51 & 0,15 \\
\hline 3 & 372 & 202 & 0,54 & 3 & 400 & 202 & 0,51 \\
\hline 7 & 358 & 250 & 0,70 & 7 & 423 & 207 & 0,49 \\
\hline 28 & 413 & 318 & 0,77 & 28 & 663 & 487 & 0,73 \\
\hline
\end{tabular}




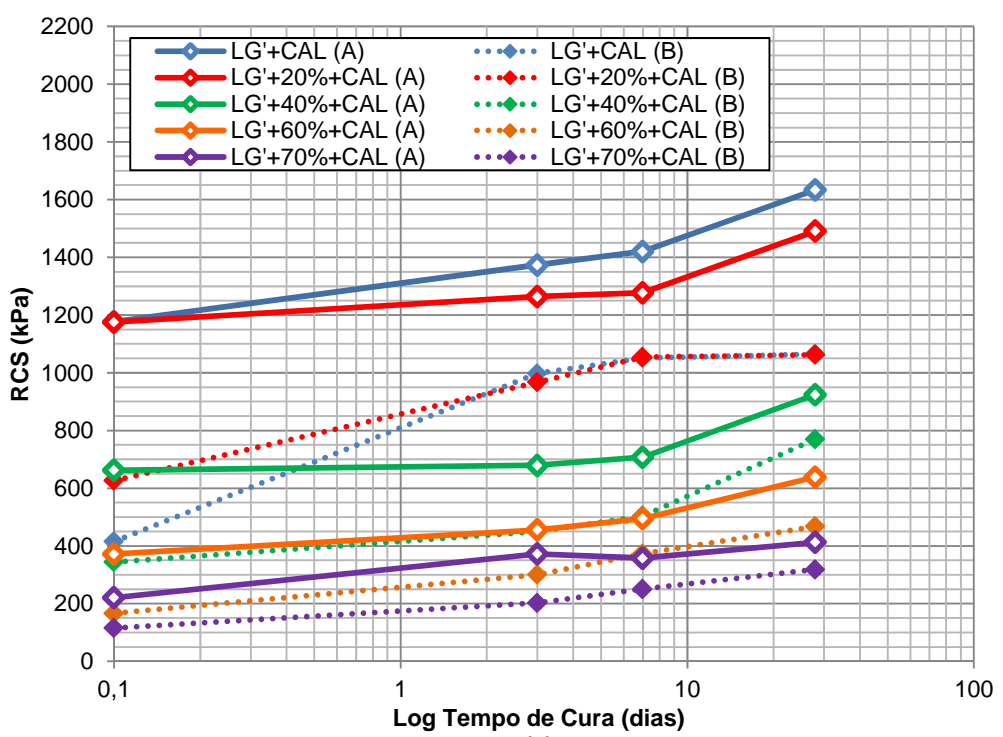

(a)

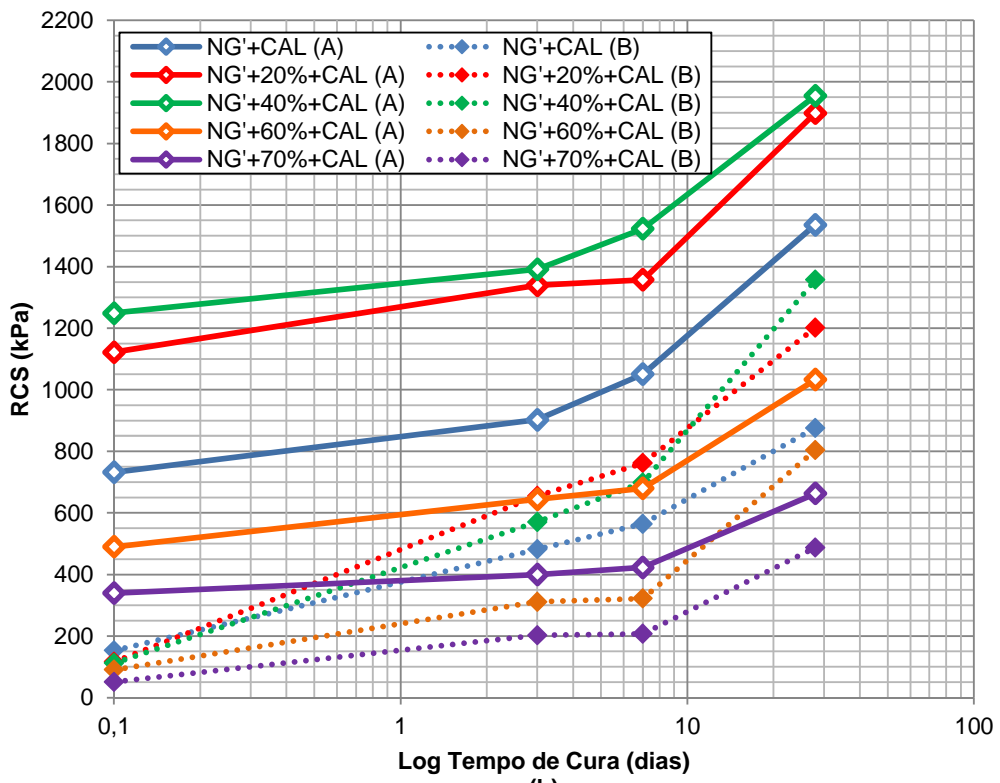

(b)

Figura 8. Resistência à compressão simples das misturas solo-areia-cal para 0, 3, 7 e 28 dias de cura

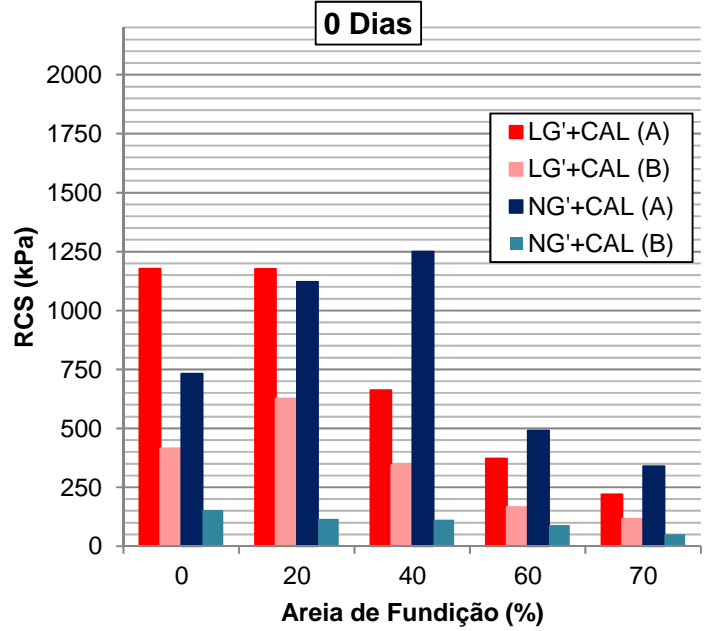

(a)

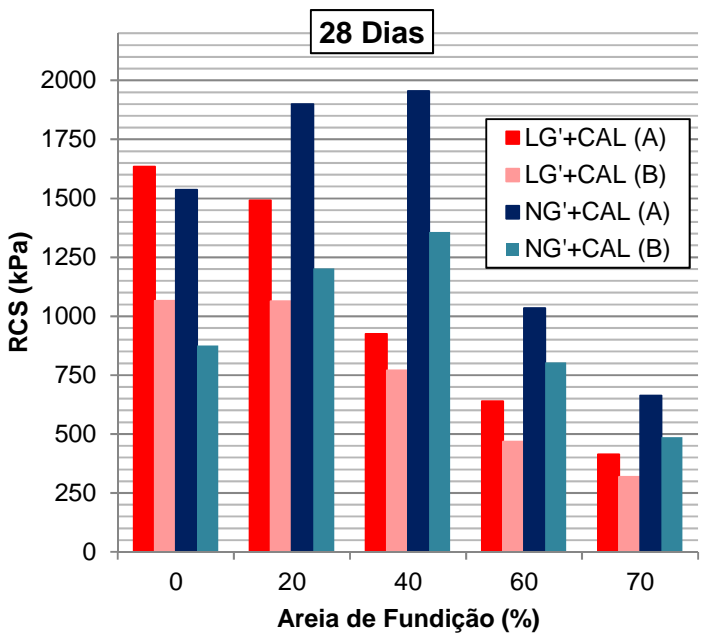

(b)

Figura 9. Resistência à compressão simples das misturas solo-areia-cal a 0 e 28 dias de cura 
Para determinar o Módulo de Resiliência $\left(M_{R}\right)$ das misturas, foi executado o ensaio triaxial cíclico, segundo a norma AASHTO T 307-99, para níveis de tensões típicos de camadas de bases e sub-bases de pavimentos. Este ensaio foi realizado em corpos-de-prova dos grupos solo-areia e soloareia-cal a 0 e 28 dias de cura. As dimensões dos corpos de prova utilizados foram de $10 \mathrm{~cm}$ de diâmetro e $20 \mathrm{~cm}$ de altura. Os valores de $\mathrm{MES}_{\max }$ e $\mathrm{W}_{\text {ot }}$ obtidos no ensaio de mini-CBR na energia intermediária foram empregados para a produção dos corpos.

Segundo diversos autores (Ferreira, 2002; Medina e Motta, 2005; Klinsky 2008) o Modelo Composto, descrito na Equação 1, é o que apresenta melhor correlação na representação do Módulo de Resiliência $\left(M_{R}\right)$, independente da distribuição granulométrica do solo. Por esta razão, este modelo foi utilizado para obter uma estimativa do valor do módulo de resiliência das misturas. As tensões empregadas no cálculo foram $\sigma_{3}=137,9 \mathrm{kPa}$ e $\sigma_{\mathrm{d}}=275,8 \mathrm{kPa}$, que correspondem ao último par de tensões do ensaio triaxial cíclico (AASHTO T 307-99).

$$
M_{R}=k_{1} \sigma_{3}^{k_{2}} \sigma_{d}^{k_{3}}
$$

As Figuras 10a e 10b apresentam, respectivamente, os valores de $M_{R}$ a 0 e 28 dias de cura resultantes dos cálculos realizados para as condições anteriormente descritas. Notase que, para 0 e 28 dias de cura, o valor de $M_{R}$ das misturas aumenta com a adição de cal, com exceção da mistura com $70 \%$ de areia de fundição a 0 dias de cura. Por outro lado, observa-se que o valor de $M_{R}$ das misturas solo-areia-cal aumenta consideravelmente aos 28 dias de cura.

No caso do solo LG'+Cal, o maior valor de $M_{R}(2.522$ $\mathrm{MPa}$ ) foi obtido na mistura sem a adição do resíduo. Já no solo $\mathrm{NG}^{\prime}+\mathrm{Cal}$, a mistura com $40 \%$ de areia de fundição apresentou o maior valor de $M_{R}$ (3.113 MPa). Little (1999) afirma que a adição de cal a solos reativos induz incrementos do valor de $M_{R}$ de até $1000 \%$ aos 28 dias de cura. Esse autor ainda obteve, através de retroanálise, valores de $M_{R}$ de $210 \mathrm{MPa}$ até $3.500 \mathrm{MPa}$, para sub-bases estabilizadas com cal.

Deve-se ressaltar que valores elevados de módulo de resiliência de solos, analisados isoladamente, não garantem desempenho satisfatório desses materiais em camadas de

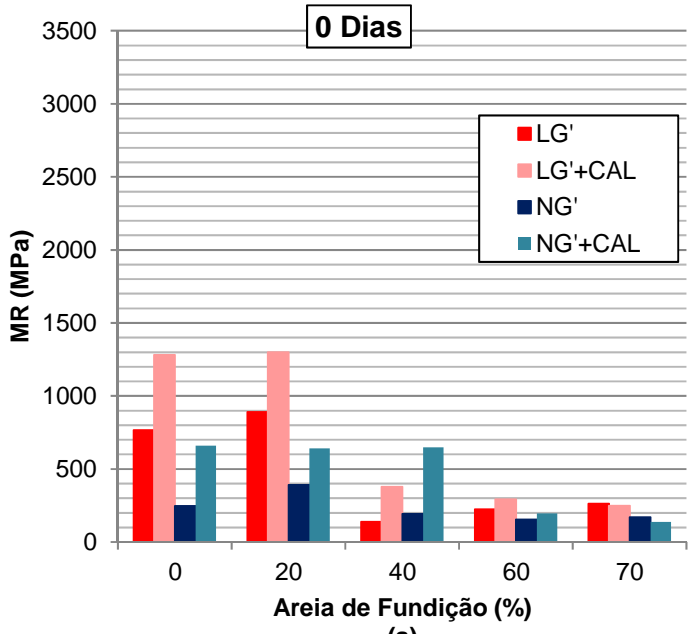

(a) pavimentos, pois o ensaio é geralmente realizado nas condições de massa específica seca máxima e umidade ótima, não levando em consideração variações no teor de umidade pós-compactação (secagem e umedecimento) e suas respectivas influências na contração, expansão e perda de suporte desses materiais.

\section{CONCLUSÕES}

A partir dos resultados obtidos dos ensaios conclui-se que:

- a adição de areia de fundição aos solos argilosos LG' e NG' estudados reduziu os Limites de Consistência (LL e IP). A adição de cal às misturas soloareia também produziu esse mesmo efeito;

- segundo a classificação MCT, solos com matriz LG' e adição de 40, 60 e 70\% de resíduo, com e sem cal, e solos com matriz NG' e adição de 60 e $70 \%$ de resíduo e 3\% de cal produziriam misturas de comportamentos semelhantes ao de um solo Laterítico Arenoso (LA'), material ideal para utilização em bases e sub-bases de pavimentos de rodovias de baixo volume de tráfego (Nogami e Villibor, 1995);

- foi constatada a redução da umidade ótima e o aumento da massa específica seca máxima com o aumento do teor de areia de fundição adicionado aos solos. Já a adição de 3\% de cal produziu aumento da umidade ótima e diminuição da massa específica seca máxima;

- os valores de mini-CBR após 24 horas de imersão aumentaram com o incremento do teor de areia de fundição, tanto para os solo-areia LG' e como para os NG'. De modo geral, para os grupos solo-areiacal, os maiores valores de mini-CBR foram obtidos para a condição na qual os corpos-de-prova foram curados durante 24 horas em câmara úmida e, logo após, imersos durante 24 horas;

- a redução da expansão com o aumento do teor de areia de fundição foi mais notória para os solos cuja matriz era NG'. A adição de 3\% de cal nas misturas solo-areia eliminou a expansão e reduziu significativamente a contração;

- as misturas de solo-areia-cal oriundas da matriz NG’ mostraram valores de resistência à compressão

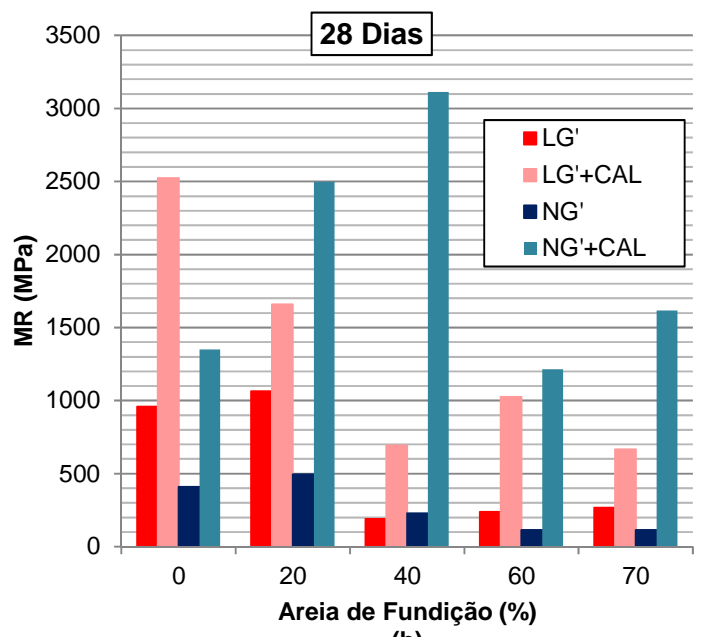

(b)

Figura 10. Módulo de resiliência das misturas solo-areia e solo-areia-cal a 0 e 28 dias de cura 
simples maiores na condição seca do que as misturas da matriz LG'; contudo, as perdas de resistência resultantes da imersão dos corpos-de-prova por 4 horas foi inferior nas misturas solo-areia-cal da matriz LG'; e

- a partir dos resultados dos ensaios triaxiais cíclicos pode se concluir que a presença da cal nos solos LG' e NG' aumenta os valores dos módulos de resiliência e que esse aumento é mais importante após 28 dias de cura.

Com base nas exigências estabelecidas na especificação ET-DE-P00-015a do DER-SP (2005), Sub-Base ou Base de Solo Arenoso Fino de Comportamento Laterítico - SAFL, pode se afirmar que o solo LG' com adição de 60 e $70 \%$ de areia de fundição poderia ser utilizado como material de construção de sub-bases e bases de pavimentos de baixo volume de tráfego.

Os solos $\mathrm{NG}^{\prime}+20 \%+\mathrm{Cal} ; \quad \mathrm{NG}^{\prime}+40 \%+\mathrm{Cal}$ e LG'+20\%+Cal apresentaram valores de resistência à compressão simples superiores a $1.030 \mathrm{kPa}$ após 28 dias de cura, critério estabelecido pelo Procedimento Illinois apresentado no State of the Art 5 - Lime Stabilization (TRB, 1987), como mínimo para utilização em camadas de base de pavimentos. Já os solos NG'+60\%+Cal e LG'+40\%+Cal apresentam resistência à compressão simples superior a $690 \mathrm{kPa}$ após 28 dias de cura, o que possibilitaria seu uso como material de construção de sub-bases de pavimentos segundo o mesmo procedimento do TRB.

\section{REFERÊNCIAS BIBLIOGRÁFICAS}

ABIFA (2011 Reporte de dados de produção de fundidos no Brasil. Associação Brasileira de Fundição. Disponível em; <http://www.abifa.com.br>. Acesso em 11/6/2011.

Corrêa, F.C. (1989) Contribuição à estabilização do Latossolo Roxo. Tese (Doutorado). Escola de Engenharia de São Carlos, Universidade de São Paulo. São Carlos.

DEDINI (2008) Relatório de Sustentabilidade 2008. Dedini S/A Indústrias de Base.

DER-SP (2005) Especificações Técnicas - Pavimentação. ET-DE-P00015A, Sub-base ou Base de Solo Arenoso Fino de Comportamento Laterítico - SAFL. Departamento de Estradas de Rodagem, São Paulo.

Ferreira, J. G. H. M. (2002) Elaboração e análise da base de dados de ensaios triaxiais dinâmicos da COPPE/UFRJ. Dissertação (Mestrado). PEC, COPPE/UFRJ. Rio de Janeiro.

Guney, Y.; A. H. Aydilek e M. M. Demirkan (2006) Geoenviromental behavior of foundry sand amended mixtures for highway subbases. Waste Management, v. 26, p. 932-945.

Klinsky, L. M. G. (2008) Proposta de Reaproveitamento de areia de fundição em sub-bases e bases de pavimentos flexíveis, através de sua incorporação a solos argilosos. Dissertação (Mestrado). Escola de Engenharia de São Carlos, Universidade de São Paulo. São Carlos.

Leandro, R. P. (2005) Estudo laboratorial acerca da possibilidade de aproveitamento da cinza pesada de termelétrica em bases e subbases de pavimentos flexíveis. Dissertação (Mestrado). Escola de Engenharia de São Carlos, Universidade de São Paulo. São Carlos.

Lima, D. C. (1981) Algumas considerações relativas a aspectos da estabilização dos solos, em particular à estabilização solo-cal. Dissertação (Mestrado). Escola de Engenharia de São Carlos, Universidade de São Paulo. São Carlos.

Little, N. D. (1999) Evaluation of structural properties of lime stabilized soils and aggregates. Volume 1: Summary of findings. National Lime Association. Estados Unidos.

McIntyre, S.W. et al. (1992) Beneficiation and Reuse of Foundry Sand Residuals: A Preliminary Report. Transactions of the American Foundry men's Society, v. 100, p. 201-208.
Medina, J. e L. M. G. Motta (2005) Mecânica dos Pavimentos. Livro, $2^{\mathrm{a}}$ Edição. Rio de Janeiro.

National Lime Association (2006) Mixture Design and testing procedures for Lime Stabilized Soil. Technical Brief, LIME the versatile Chemical.

Nogami, J. S. e D. F. Villibor (1995) Pavimentação de baixo custo com solos lateríticos. Ed. Vilibor: São Paulo. 213 p.

Oliveira, S. M. F. (2005) Estudo do comportamento mecânico de misturas de fosfogesso e cal para utilização na construção rodoviária. Dissertação (Mestrado). Escola de Engenharia de São Carlos, Universidade de São Paulo. São Carlos.

Thompson, M. R. (1970) Soil Stabilization of Pavement Systems - State of the Art. Technical Report - Department of the Army, Construction Engineering Research Laboratory, Champaign, Illinois.

TRB (1987) Lime Stabilization: Reactions, Properties, Design, and Construction, State of the Art Report 5. Report prepared by TRB Committee on Lime and Lime-Fly Ash Stabilization, Transportation Research Board, National Research Council, Washington, D.C.

Yusuf, F. A. M. S.; N. D. Little e S. L. Sarkar (2001) Evaluation of Structural Contribution of Lime Stabilization of Subgrade Soils in Mississippi. Transportation Research Record 1757, p. 22-31. 